\title{
Prescription characteristics of phosphate binders in a high pill burden for hemodialysis patients
}

Nobuo Nagano ${ }^{1,2^{*}} \mathbb{D}$, Kyoko Ito ${ }^{1}$, Takashi Ono ${ }^{1}$, Yuichi Ariyoshi', Soichiro Masima ${ }^{1}$, Hajime Kobayashi ${ }^{1}$, Tetsuo Ando ${ }^{1}$, Takaaki Tsutsui ${ }^{1}$ and Tetsuya Ogawa ${ }^{1,2}$

\begin{abstract}
Background: Dialysis patients have to take many oral drugs, causing a high pill burden. Phosphate binders (PBs) account for a large proportion of daily pill burden; however, the relationship between patient background and prescription status of PBs is not clear.

Methods: We clarified the characteristics of PBs in the total daily pill burden by analyzing the drugs prescribed for 533 chronic hemodialysis patients in our facility.

Results: An average of nine different types of oral drugs was prescribed for each patient. The mean and median values of total pill burden were 15.1 and 14.1 pills/day/patient, respectively. The total pill burden showed a significant negative correlation with age and a significant positive correlation with dialysis vintage. In addition, the total pill burden was significantly higher in males than in females. However, there was no difference in the pill burden between patients with and without diabetes mellitus (DM). PBs were prescribed to 409 patients (76.7\%), and the mean pill burden derived from PBs was 6.44 pills/day/patient. This was by far the highest of all 35 different drug categories and accounted for $32.84 \%$ of all pills. Multiple regression analysis demonstrated that independent predictors of total pill burden were age, dialysis vintage, DM, and serum phosphorus (P) levels, and all these variables, except DM, were also independent predictors of pill burden from PBs. These variables were also selected when considering the use of calcimimetics.

Conclusions: A high pill burden is more likely to occur in younger patients with longer dialysis vintage, DM, higher serum P levels, and prescription of calcimimetics. In addition, PB was the single largest contributor to the total pill burden that positively and linearly linked to serum P levels. Therefore, P management is a high-priority issue in the mitigation of high pill burdens in dialysis patients.
\end{abstract}

Keywords: High pill burden, Polypharmacy, Phosphate binder, Calcimimetics, Hemodialysis patients, Serum phosphorus levels

\footnotetext{
* Correspondence: n_nagano@hidaka-kai.com

${ }^{1}$ Kidney Disease and Dialysis Center, Hidaka Hospital, Hidaka-kai, Takasaki,

Gunma, Japan

${ }^{2}$ Department of Medicine, Tokyo Women's Medical University Medical Center

East, Tokyo, Japan
}

(c) The Author(s). 2021 Open Access This article is licensed under a Creative Commons Attribution 4.0 International License, which permits use, sharing, adaptation, distribution and reproduction in any medium or format, as long as you give appropriate credit to the original author(s) and the source, provide a link to the Creative Commons licence, and indicate if changes were made. The images or other third party material in this article are included in the article's Creative Commons licence, unless indicated otherwise in a credit line to the material. If material is not included in the article's Creative Commons licence and your intended use is not permitted by statutory regulation or exceeds the permitted use, you will need to obtain permission directly from the copyright holder. To view a copy of this licence, visit http://creativecommons.org/licenses/by/4.0/ The Creative Commons Public Domain Dedication waiver (http://creativecommons.org/publicdomain/zero/1.0/) applies to the data made available in this article, unless otherwise stated in a credit line to the data. 


\section{Background}

Polypharmacy causes a variety of problems, including adverse drug interaction events, lower quality of life, inappropriate (incorrect, over-, and under-) prescriptions, poor medication adherence, and increased health care costs [1-3]. Although there is currently no clear-cut definition of polypharmacy [2, 4], chronic dialysis patients have to take many pills of oral drugs, as such bear high pill burden, to treat multiple comorbidities [5-12]. The symptoms and severity of complications vary greatly among dialysis patients. Therefore, it is considered that a situation of high pill burden would be affected by the patient background such as gender, age, dialysis vintage, and presence or absence of diabetes mellitus (DM).

It has been reported that phosphate binders (PBs) account for a large proportion of the daily pill burden in dialysis patients $[6,10,11]$. However, there are few studies clarifying the relationship between patient background and prescription status of PBs in a high pill burden. In addition, some new PBs and calcimimetics have recently become available for the treatment of chronic kidney disease-mineral and bone disorder (CKD-MBD) in dialysis patients. In this study, we investigated the characteristics of PBs in cases of high pill burden by analyzing the drugs prescribed for 533 chronic hemodialysis patients in Japan.

\section{Methods}

\section{Study design}

This single-center cross-sectional study was approved by the Hidaka Hospital Medical Ethics Committee. Out of 546 chronic hemodialysis patients at our dialysis center of the Heisei Hidaka clinic (Gunma, Japan), we excluded 13 patients who were not on stable hemodialysis (3 times a week) due to surgery or hospitalization during the study period (February 2020). Because we had observed small increases in serum phosphorus (P) levels in our dialysis patients at the end and beginning of every year, we avoided this period and set the study period in February. We analyzed the drug prescription records and routine blood chemistries (serum corrected calcium [Ca], P, and intact parathyroid hormone [i-PTH] levels) of 533 patients who were prescribed at least one pill for 1 month.

\section{Classification of oral drugs}

The oral drugs were basically classified according to the drug efficacy classification numbers of Standard Commodity Classification for Japan (JSCC; under the jurisdiction of Ministry of Internal Affairs and Communications) [13] described in each drug package insert. As exceptions, PBs and potassium binders are both denoted by 87219 as "other cardiovascular agents" and calcimimetics (evocalcet $[14,15]$ ) is denoted by 873999 as "other agents affecting metabolism, not elsewhere classified," so they were independently classified as "PBs," "potassium binders," and "calcimimetics." Vitamin preparations were divided into two categories of "vitamin D receptor activator (VDRA)" and "vitamin preparations (exc. VDRA)." Antibiotic preparations and synthetic antimicrobials were represented as "antimicrobials." A compounded drug consisting of two different categories was classified into the main therapeutic category. The 18 categories of drugs prescribed to less than 10 patients for 1 month were collectively classified as "others." As a result, 269 different types of oral drugs (322 types, including different dose formulations) were classified into 35 categories.

\section{Total pill burden}

The dosage units of tablets, capsules, packets (for powder, granule, and dry syrup), small plastic cups (for jelly), and small plastic vials (for oral solution) prescribed for 1 month were all counted as one pill for convenience of calculation. Troches, gargles, nutritional drinks, inhalants, and oral ointments were excluded from the count.

The total number of pills of all drugs prescribed for 533 patients for 1 month was calculated (all pills). Similarly, the number of pills prescribed for 1 month was totaled in each drug category (categorized pills). The ratio (\%) of categorized pills to all pills was calculated and then ranked from 1 st to 35 th. Also, the number of patients was counted for each drug category. "Total pill burden" was defined as how many all pills were prescribed per patient per day. Similarly, the daily pill burden derived from drugs belonging to category A was defined as "pill burden from A."

\section{PBs}

Ca carbonate, lanthanum (La) carbonate, ferric citrate hydrate, sucroferric oxyhydroxide, sevelamer hydrochloride $(\mathrm{HCl})$, and bixalomer were prescribed during the study period in our facility. Because the number of prescribed patients was relatively small, total pills of ferric citrate hydrate (74 patients) and sucroferric oxyhydroxide (31 patients) were expressed as the pill burden from "iron (Fe)-based PBs." Similarly, total pills of sevelamer $\mathrm{HCl}$ (20 patients) and bixalomer (19 patients) were expressed as the pill burden from "polymeric PBs." For further analysis, PBs were classified into two categories: Ca-based PBs (Ca carbonate) and non-Ca-based PBs (PBs other than Ca carbonate).

\section{CKD-MBD-related drugs}

We examined whether the prescription of CKD-MBDrelated drugs excluding PBs would affect the total pill burden and pill burden from PBs. The following oral and intravenous (IV) calcimimetics and VDRAs used at our facility were defined as CKD-MBD-related drugs: oral calcimimetics: evocalcet $[14,15]$; oral VDRA: 
alfacalcidol and calcitriol; IV calcimimetics: etelcalcetide $\mathrm{HCl}$ [15]; and IV VDRA: calcitriol and maxacalcitol (22oxacalcitriol) [16].

\section{Statistical analyses}

For numerical variables, normality was checked using the Shapiro-Wilk test. Normally distributed data were expressed as mean \pm standard deviation, while nonnormally distributed data were expressed as median (interquartile range). Although the number of pills was non-normally distributed data, it was expressed as the mean values instead of the median values in order to make the difference clear.

A two-group comparison was performed with the Fisher exact test, unpaired $t$ test, or the Mann-Whitney $U$ test. A single correlation was analyzed using Spearman's correlation analysis. Additionally, the age and dialysis vintage were divided into quintiles, and the Kruskal-Wallis test was used for comparisons between quintiles. Multiple regression analysis was performed using a stepwise method. Statistical analysis was performed using SPSS software (version 21, IBM, NY, USA). $P$ values less than 0.05 were considered statistically significant.

\section{Results}

\section{Total pill burden}

The patient background, dialysis condition, serum chemistries, comorbidities, and total prescription status of the 533 patients are shown in Table 1 . Approximately 9 different types of oral drugs out of 269 types were prescribed per patient for a month. The mean and median values of total pill burden were $15.1 \pm 7.6$ and 14.1 (10.0-18.7) pills/day/patient, respectively.

The total pill burden negatively correlated with age and positively correlated with dialysis vintage, serum $\mathrm{P}$ levels, serum albumin (Alb) levels, and normalized protein catabolic rate (nPCR) (Table 2). Similarly, the quintile analysis clearly showed that the total pill burden gradually decreased with age and increased with dialysis vintage (Fig. 1). The total pill burden was significantly higher in males than in females; however, there was no difference in the pill burden between patients with and without DM (Fig. 2 and Table 3).

\section{Pill burden from each drug category}

PBs were prescribed to the largest number of patients, 409 patients (76.7\%), and the mean value of the pill burden from PBs was 6.44 pills/day/patient (Table 4). This was by far the highest and accounted for $32.84 \%$ of all pills. In individual PBs, Ca carbonate constituted about half of all PBs and also accounted for $16.37 \%$ of all pills. The second-largest contributor was "antihypertensives," which accounted for only $8.36 \%$ of all pills. In oral CKD-
MBD-related drugs, "calcimimetics" ranked 11th and "VDRA" ranked 14th. The pill burden from both PBs and oral CKD-MBD-related drugs accounted for $36.86 \%$ of all pills.

\section{Pill burden from all PBs}

The pill burden from all PBs showed a negative correlation with age and positive correlations with dialysis vintage, serum $\mathrm{P}$ levels, serum Alb levels, and nPCR (Table 2). These results were similar to those observed in the total pill burden. The quintile analysis also clearly showed that the pill burden from PBs, the single largest contributor, gradually decreased with age and increased with dialysis vintage (Fig. 1). There was no significant difference in the percentage of patients treated with PBs between males and females and between patients with and without DM (Table 3). In contrast, the pill burden from PBs was significantly higher in males and in nonDM patients than in females and DM patients, respectively (Fig. 2 and Table 3).

\section{Pill burden from individual PBs}

The pill burden from Ca carbonate negatively correlated with age and positively correlated with dialysis vintage and serum P levels (Table 2). Similarly, the pill burden from La carbonate correlated with age and serum $\mathrm{P}$ levels, and Fe-based PBs correlated with age and dialysis vintage. Fewer patients were prescribed polymeric PBs (Tables 3 and 4), and the pill burden from polymeric PBs was not correlated with any variable (Table 2).

The percentage of patients who were prescribed $\mathrm{Ca}$ carbonate did not differ between males and females and between patients with and without DM, while more pills were prescribed in non-DM patients than in DM patients (Table 3). La carbonate was more prescribed in males and in non-DM patients than in females and DM patients, respectively.

\section{CKD-MBD-related drugs}

The total pill burden was significantly higher in both oral and IV calcimimetics users when compared with non-users (Table 5). Similar results were observed in the pill burden from all PBs. On the other hand, only in oral calcimimetics users, the pill burden from both Ca-based and non-Ca-based PBs was significantly higher. The pill burden from all $\mathrm{PBs}$ and from Ca-based $\mathrm{PB}$ in oral VDRAs users was less than those in non-users.

\section{Multiple regression analysis}

Multiple regression analysis showed that independent predictors of total pill burden were age, dialysis vintage, DM, and serum P levels, and all these variables, except DM, were also independent predictors of pill burden from PBs (Table 6). This result was also consistent when 
Table 1 Patient background, dialysis condition, serum chemistries, comorbidities, and prescription status

\begin{tabular}{|c|c|c|}
\hline Patients & $n$ & 533 \\
\hline Gender (male) & n (\%) & $362(67.9)$ \\
\hline Age & years & $\begin{array}{l}71.3\left(63.8^{-}\right. \\
78.0)\end{array}$ \\
\hline Dialysis vintage & years & $5.5(2.1-10$. \\
\hline Age of starting dialysis & years & $\begin{array}{l}63.9\left(52.8^{-}\right. \\
73.1)\end{array}$ \\
\hline \multicolumn{3}{|l|}{ Dialysis Modality } \\
\hline $\mathrm{HD}$ & n (\%) & $306(57.4)$ \\
\hline On-line HDF & n (\%) & $227(42.6)$ \\
\hline \multicolumn{3}{|l|}{ Time } \\
\hline$<4 \mathrm{hr}$ & n (\%) & $74(13.9)$ \\
\hline $4 \mathrm{hr}$ & n (\%) & $443(83.1)$ \\
\hline $4.5 \mathrm{hr} \leq$ & n (\%) & $16(3.0)$ \\
\hline \multicolumn{3}{|l|}{ Blood flow } \\
\hline$<200 \mathrm{~mL} / \mathrm{min}$ & n (\%) & $105(19.7)$ \\
\hline $200 \mathrm{~mL} / \mathrm{min}$ & n (\%) & $214(40.2)$ \\
\hline $210 \mathrm{~mL} / \mathrm{min} \leq$ & n (\%) & $214(40.2)$ \\
\hline \multicolumn{3}{|l|}{ Dialysate Ca } \\
\hline $2.5 \mathrm{mEq} / \mathrm{L}$ & n (\%) & $365(68.5)$ \\
\hline $3.0 \mathrm{mEq} / \mathrm{L}$ & n (\%) & $168(31.5)$ \\
\hline Serum corrected Ca & $\mathrm{mg} / \mathrm{dL}$ & $8.70 \pm 0.61$ \\
\hline Serum $P$ & $\mathrm{mg} / \mathrm{dL}$ & $5.37 \pm 1.17$ \\
\hline Serum i-PTH & $\mathrm{pg} / \mathrm{mL}$ & $\begin{array}{l}182(120- \\
257)\end{array}$ \\
\hline \multicolumn{3}{|l|}{ Comorbidities } \\
\hline Diabetes mellitus (DM) & n (\%) & $310(58.2)$ \\
\hline Heart failure & n (\%) & $155(29.1)$ \\
\hline Angina & n (\%) & $85(15.9)$ \\
\hline Myocardial infarction & n (\%) & $26(4.9)$ \\
\hline Arrhythmia / Extrasystes & n (\%) & $80(15.0)$ \\
\hline Peripheral vascular disease & n (\%) & $88(16.5)$ \\
\hline Cerebral / Brainstem infarction & n (\%) & $106(19.9)$ \\
\hline Neurologic / Psychiatric disease & n (\%) & $78(14.6)$ \\
\hline Insomnia & n (\%) & $92(17.3)$ \\
\hline Gastointestinal disease & n (\%) & $332(62.3)$ \\
\hline Constipation & n (\%) & $141(26.5)$ \\
\hline Diarrhea & n (\%) & $24(4.5)$ \\
\hline Respiratory disease & n (\%) & $92(17.3)$ \\
\hline Hepatobiliary disease & n (\%) & $132(24.8)$ \\
\hline Pancreatic disease & n (\%) & $27(5.1)$ \\
\hline Thyroid disease & n (\%) & $52(9.8)$ \\
\hline Ocular disease & n (\%) & $263(49.3)$ \\
\hline Joint and bone disease & n (\%) & $221(41.5)$ \\
\hline Previous fracture & n (\%) & $65(12.2)$ \\
\hline
\end{tabular}

Table 1 Patient background, dialysis condition, serum

\begin{tabular}{|c|c|c|}
\hline Malignancy (including history) & n (\%) & $135(25.3)$ \\
\hline $\begin{array}{l}\text { Gangrene, Cellulitis, Decubitus, Skin } \\
\text { ulcer }\end{array}$ & n (\%) & $31(5.8)$ \\
\hline Previous parathyroidectomy (PTx) & n (\%) & $10(1.9)$ \\
\hline Prescription medical doctors & $n$ & 26 \\
\hline \multicolumn{3}{|l|}{ Different types of oral drugs } \\
\hline mean $\pm S D$ & $\begin{array}{l}\text { types/month/ } \\
\text { patient }\end{array}$ & $9.2 \pm 3.2$ \\
\hline median (Q1-Q3) & $\begin{array}{l}\text { types/month/ } \\
\text { patient }\end{array}$ & $9(7-11)$ \\
\hline \multicolumn{3}{|l|}{ Total pill burden } \\
\hline mean $\pm S D$ & pills/day/patient & $15.1 \pm 7.6$ \\
\hline median (Q1-Q3) & pills/day/patient & $\begin{array}{l}14.1(10.0- \\
18.7)\end{array}$ \\
\hline
\end{tabular}

HD hemodialysis, HDF hemodialysis filtration, Q1 first quartile, Q3 third quartile

adding the use of calcimimetics to the independent variables in model 2. The prescriptions of oral and IV calcimimetics were independent positive predictors of the total pill burden. In addition, the use of oral calcimimetics was also an independent positive predictor of the pill burden from PBs.

\section{Discussion}

The present study highlights some important results that could lead to a clue to reduce the high pill burden in dialysis patients as follows: The independent predictors of total pill burden were age, dialysis vintage, DM, and serum $P$ levels, and all these variables except DM were also independent predictors of the pill burden from PBs. In addition, these variables were also selected when considering the use of calcimimetics. Furthermore, PB was the single largest contributor to the total pill burden that positively and linearly linked to serum $\mathrm{P}$ levels. Therefore, $\mathrm{P}$ management is a high-priority issue in the mitigation of high pill burdens in dialysis patients.

Nine different types of oral drugs were prescribed to our patients. This is less than those found in other previous reports $[5,11]$ and is similar to one report [6]. In addition to the differences in approved drugs between countries, prescribed drug types depend on the severity of patients between large general hospitals and outpatient maintenance hemodialysis facilities. Furthermore, many new drugs have recently been launched in the market. Therefore, it is obvious that the number of drug types prescribed for dialysis patients varies depending on countries, facility types, and years in which they were reported. On the other hand, the present result (9 types) is slightly higher than that in European CKD patients not on dialysis (8 types) $[17,18]$. Thus, it is intriguing to examine consecutive changes in the number of drug 


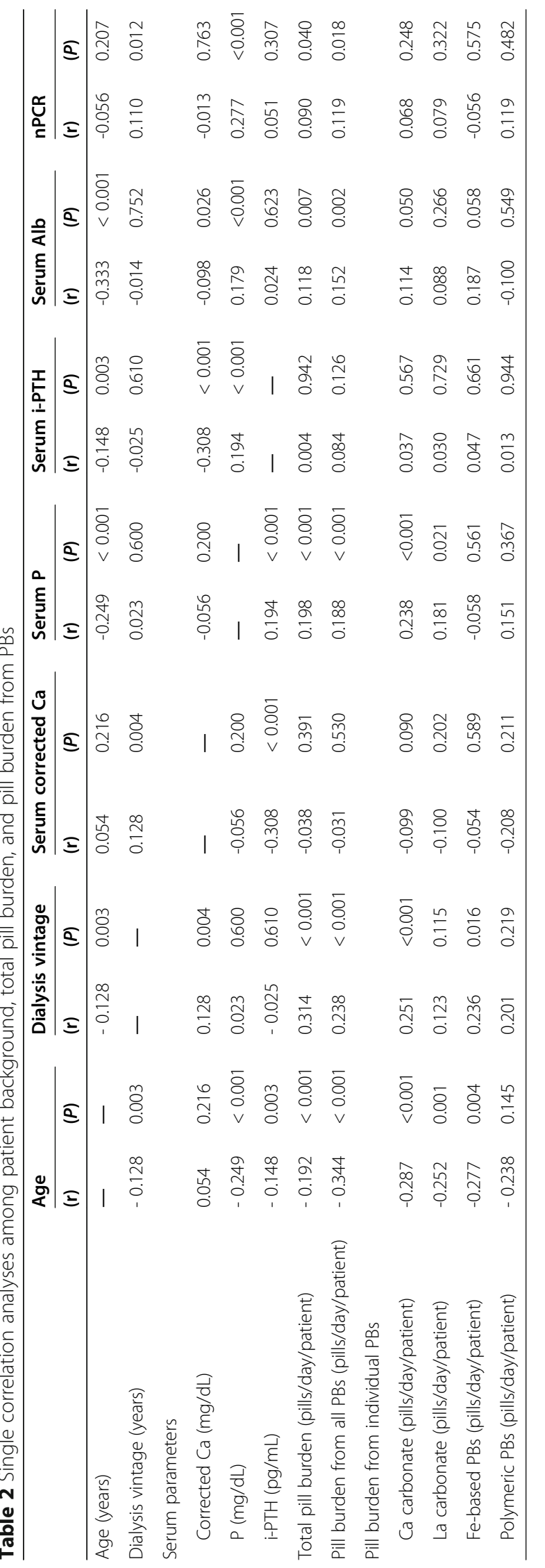


(a) Age

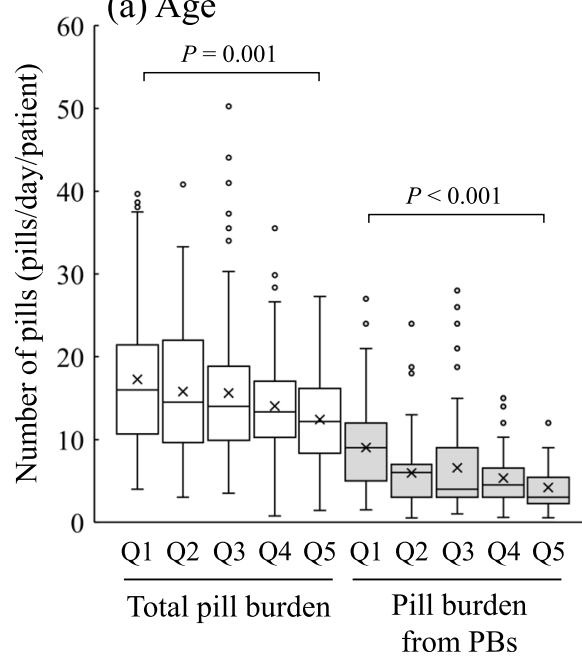

(b) Dialysis vintage

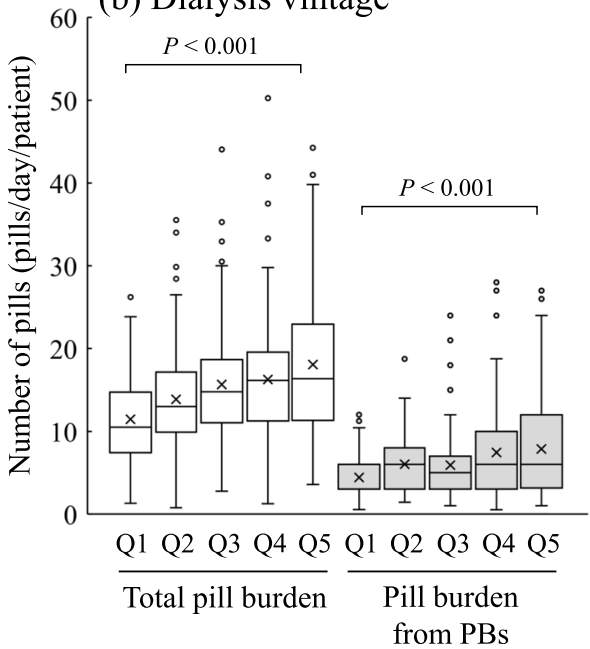

Fig. 1 Total pill burden (white columns) and pill burden from PBs (gray columns) in quintiles by age (a) and dialysis vintage (b). Q1-5; first-fifth quintiles

types prescribed before and after the initiation of dialysis in the same cohorts.

The mean (15.1) and median (14.1) values of the total pill burden in this study are lower than those in previous reports $[6,8,10-12]$. On the other hand, the pill burden from PBs (mean 6.4 pills) is much less than those found in other two reports $[6,11]$ and only slightly fewer than that (mean 6.7 pills) in Japan in the international Dialysis Outcomes and Practice Patterns Study (DOPPS) [9]. Therefore, it is confirmed that the $\mathrm{PB}$ prescription status at our facility is almost average in Japan. However, a simple comparison with the past investigation may not make much sense, because new types of PBs such as ferric citrate hydrate, sucroferric oxyhydroxide, and bixalomer are now available. The proportion of $\mathrm{PBs}$ in all pills $(32.84 \%)$ was much lower than those in other facilities $[6,11]$, although it is a consistent result that this is an outstandingly high proportion compared to other drug categories $[6,10,11]$. In our facility, IV calcimimetics (etelcalcetide $\mathrm{HCl}$ ) and new oral calcimimetics (evocalcet) [14, 15] have been actively used, and thus, serum i-PTH levels in $63.1 \%$ of patients were within the target range of the Japanese Society for Dialysis Therapy (JSDT) guidelines $(60-240 \mathrm{pg} / \mathrm{mL})$ [19]. Lower PTH reduces $\mathrm{P}$ mobilization from the bone and facilitates $\mathrm{P}$ management. In addition, we enthusiastically provide
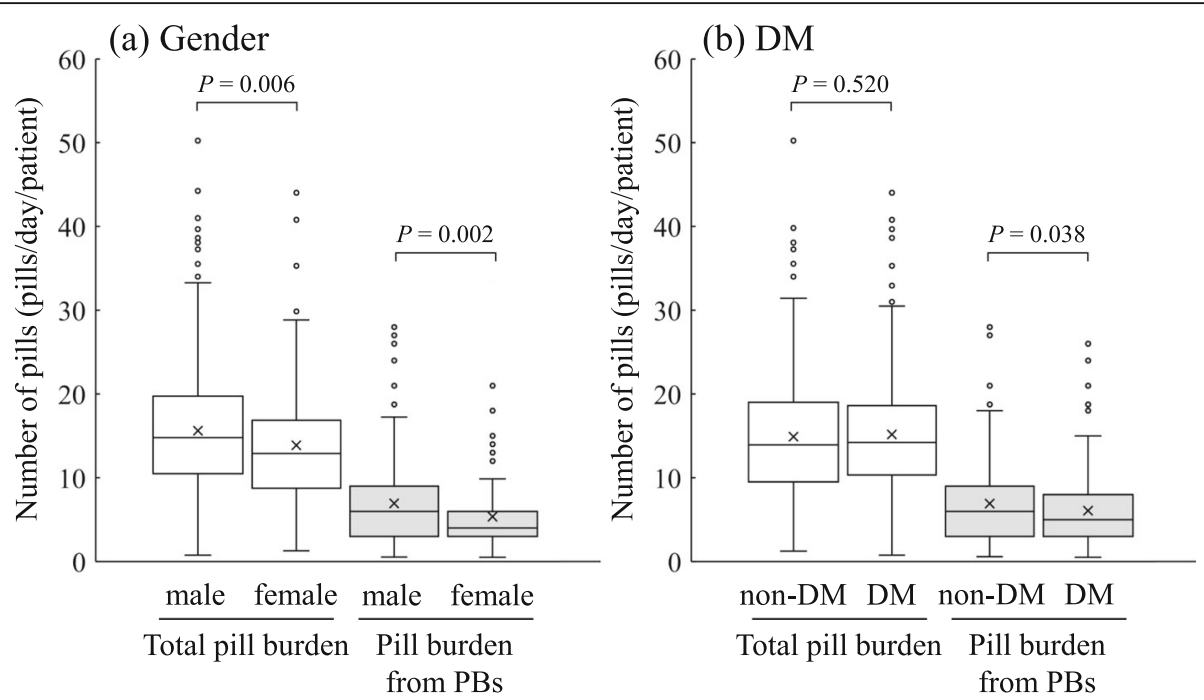

Fig. 2 Comparison of total pill burden (white columns) and pill burden from PBs (gray columns) between males and females (a) and presence and absence of DM (b) 
Table 3 Comparison of patient background, total pill burden, number of patients, and pill burden from PBs between males and females and presence and absence of DM

\begin{tabular}{|c|c|c|c|c|c|c|c|c|}
\hline & & Total & Gender (male) & Gender (female) & & non-DM & DM & \\
\hline & & $533(100 \%)$ & $362(67.9 \%)$ & $171(32.1 \%)$ & $(P)$ & $223(41.8 \%)$ & $310(58.2 \%)$ & $(P)$ \\
\hline Age & years & $71.3(63.8-78.0)$ & $70.4(61.2-76.0)$ & $73.3(66.7-81.5)$ & $<0.001$ & $72.3(64.4-79.4)$ & $71.0(63.0-76.2)$ & 0.093 \\
\hline Diabetes (yes) & n (\%) & $310(58.2)$ & $224(61.9)$ & $86(50.3)$ & 0.008 & - & - & - \\
\hline Dialysis vintage & years & $5.5(2.1-10.8)$ & $6.1(2.1-11.4)$ & $4.5(2.2-9.1)$ & 0.094 & $8.2(2.9-17.1)$ & $4.5(1.8-7.7)$ & $<0.001$ \\
\hline \multicolumn{9}{|l|}{ Serum MBD parameters } \\
\hline Corrected Ca & $\mathrm{mg} / \mathrm{dL}$ & $8.70 \pm 0.61$ & $8.61 \pm 0.62$ & $8.88 \pm 0.55$ & $<0.001$ & $8.74 \pm 0.63$ & $8.67 \pm 0.60$ & 0.258 \\
\hline$P$ & $\mathrm{mg} / \mathrm{dL}$ & $5.37 \pm 1.17$ & $5.42 \pm 1.22$ & $5.27 \pm 1.04$ & 0.174 & $5.51 \pm 1.19$ & $5.27 \pm 1.14$ & 0.019 \\
\hline i-PTH & $\mathrm{pg} / \mathrm{mL}$ & $182(120-257)$ & $189(132-260)$ & $168(107-252)$ & 0.091 & $182(122-267)$ & $183(117-256)$ & 0.596 \\
\hline \multicolumn{9}{|l|}{ Nutritional status } \\
\hline Serum Alb & $\mathrm{g} / \mathrm{dL}$ & $3.78 \pm 0.33$ & $3.81 \pm 0.33$ & $3.72 \pm 0.33$ & 0.002 & $3.79 \pm 0.33$ & $3.78 \pm 0.34$ & 0.913 \\
\hline $\mathrm{nPCR}$ & $\mathrm{g} / \mathrm{kg} /$ day & $0.772 \pm 0.139$ & $0.758 \pm 0.132$ & $0.800 \pm 0.150$ & 0.001 & $0.795 \pm 0.137$ & $0.755 \pm 0.139$ & 0.003 \\
\hline Total pill burden (mean) & pills/day/patient & $15.1 \pm 7.6$ & $15.6 \pm 7.8$ & $13.9 \pm 7.1$ & 0.006 & $14.9 \pm 7.7$ & $15.2 \pm 7.5$ & 0.520 \\
\hline Total pill burden (median) & pills/day/patient & $14.1(10.0-18.7)$ & $14.8(10.5-19.7)$ & $12.9(8.8-16.8)$ & 0.006 & $13.9(9.6-18.9)$ & $14.2(10.4-18.6)$ & 0.520 \\
\hline \multicolumn{9}{|l|}{ Number of patients } \\
\hline All PBs & n (\%) & $409(76.7)$ & $279(77.1)$ & $130(76.0)$ & 0.435 & $178(79.8)$ & $231(74.5)$ & 0.092 \\
\hline \multicolumn{9}{|l|}{ Individual PBs } \\
\hline Ca carbonate & n (\%) & $301(56.5)$ & $207(57.2)$ & $94(55.0)$ & 0.349 & $133(59.6)$ & $168(54.2)$ & 0.122 \\
\hline La carbonate & n (\%) & $164(30.8)$ & $124(34.3)$ & $40(23.4)$ & 0.007 & $81(36.3)$ & $83(26.8)$ & 0.012 \\
\hline Fe-based PBs & n (\%) & $104(19.5)$ & $75(20.7)$ & $29(17.0)$ & 0.183 & $38(17.0)$ & $66(21.3)$ & 0.133 \\
\hline Polymeric PBs & n (\%) & $39(7.3)$ & $28(7.7)$ & $11(6.4)$ & 0.365 & $16(7.2)$ & $23(7.4)$ & 0.528 \\
\hline \multicolumn{9}{|l|}{ Pill burden from PBs } \\
\hline All PBs & pills/day/patient & $6.44 \pm 4.78$ & $6.94 \pm 5.08$ & $5.36 \pm 3.87$ & 0.002 & $6.92 \pm 4.94$ & $6.08 \pm 4.64$ & 0.038 \\
\hline \multicolumn{9}{|l|}{ Individual PBs } \\
\hline Ca carbonate & pills/day/patient & $4.36 \pm 2.01$ & $4.47 \pm 2.11$ & $4.12 \pm 1.77$ & 0.298 & $4.64 \pm 2.04$ & $4.15 \pm 1.97$ & 0.035 \\
\hline La carbonate & pills/day/patient & $3.98 \pm 2.14$ & $4.09 \pm 2.17$ & $3.64 \pm 2.03$ & 0.190 & $4.25 \pm 2.28$ & $3.72 \pm 1.97$ & 0.103 \\
\hline Fe-based PBs & pills/day/patient & $4.14 \pm 2.40$ & $4.40 \pm 2.53$ & $3.47 \pm 1.93$ & 0.066 & $4.22 \pm 3.17$ & $4.09 \pm 1.85$ & 0.511 \\
\hline Polymeric PBs & pills/day/patient & $6.10 \pm 3.34$ & $6.23 \pm 3.45$ & $5.77 \pm 3.20$ & 0.633 & $6.88 \pm 3.23$ & $5.56 \pm 3.38$ & 0.301 \\
\hline
\end{tabular}

dietary education to dialysis patients. Therefore, this may be the reason why the pill burden from PBs was lesser and the proportion of patients prescribed PBs (76.7\%) was also lower when compared to the results of another DOPPS (88\% of patients are prescribed PBs in 12 countries) [20].

The total pill burden linearly correlated with decreased age and with increased dialysis vintage and was more prevalent in males. These relationships were also observed in the pill burden from PBs. On the other hand, there was no difference in the total pill burden between DM and non-DM patients, although the pill burden from PBs was significantly more prevalent in non-DM patients. The pill burden from "antidiabetic agents" was 2.27 pills and ranked sixth in the list of contributors accounting for $4.95 \%$ of all pills. The "antidiabetic agents" were prescribed to only DM patients. In addition, serum $\mathrm{P}$ levels in DM patients were significantly lower than those in non-DM patients. This result is probably due to reduced dietary intake volume, because nPCR was significantly lower in DM patients than in non-DM patients. Thus, DM patients were prescribed lower pills from PBs instead of higher pills from "antidiabetic agents." Therefore, it is considered that there is no significant difference in the total pill burden between patients with and without DM. The above consideration is consistent with the multiple regression analysis showing that independent predictors of total pill burden were age, dialysis vintage, DM, and serum P levels, and these variables, except DM, were also independent predictors of the pill burden from PBs. These can also be explained by the fact that $\mathrm{PB}$ is the single largest contributor to the total pill burden.

The uses of oral and IV calcimimetics increased both the total pill burden and the pill burden from all PBs. This result can be explained as follows. First, the pill 
Table 4 Pill burden from each drug category

\begin{tabular}{|c|c|c|c|c|c|}
\hline \multirow{2}{*}{\multicolumn{2}{|c|}{$\begin{array}{l}\text { Categories of oral drugs } \\
\text { (35 different types) }\end{array}$}} & \multicolumn{4}{|c|}{ Pill burden and number of prescribed patients } \\
\hline & & \multirow{2}{*}{$\begin{array}{l}\text { Total pills } \\
\text { (\%) } \\
32.84\end{array}$} & \multirow{2}{*}{$\begin{array}{l}\text { Patients } \\
\text { (n) } \\
409\end{array}$} & \multirow{2}{*}{$\begin{array}{l}\text { Patients } \\
\text { (\%) } \\
76.7\end{array}$} & \multirow{2}{*}{$\begin{array}{l}\text { Daily pills } \\
\text { (pills/day/patient) } \\
6.44\end{array}$} \\
\hline 1 & Phosnhate hinders & & & & \\
\hline & Ca carbonate & 16.37 & 301 & 56.5 & 4.36 \\
\hline & La carbonate & 8.14 & 164 & 30.8 & 3.98 \\
\hline & Fe-based PBs & 5.37 & 104 & 19.5 & 4.14 \\
\hline & Polymeric PBs & 2.97 & 39 & 7.3 & 6.10 \\
\hline 2 & Antihypertensives & 8.36 & 329 & 61.7 & 2.04 \\
\hline 3 & Coronary vasodilators, antianginal agents & 8.12 & 308 & 57.8 & 2.12 \\
\hline 4 & Anticoagulants & 6.06 & 269 & 50.5 & 1.81 \\
\hline 5 & Agents for peptic ulcer & 5.52 & 307 & 57.6 & 1.44 \\
\hline 6 & Antidiabetic agents & 4.95 & 175 & 32.8 & 2.27 \\
\hline 7 & Purgatives and clysters & 3.47 & 153 & 28.7 & 1.82 \\
\hline 8 & Antidiarrheals, intestinal regulators & 2.82 & 94 & 17.6 & 2.40 \\
\hline 9 & Agents for hyperlipidemias & 2.48 & 189 & 35.5 & 1.05 \\
\hline 10 & Potassium binders & 2.33 & 98 & 18.4 & 1.90 \\
\hline 11 & Calcimimetics & 2.30 & 155 & 29.1 & 1.18 \\
\hline 12 & Antiarrhythmic agents & 2.00 & 93 & 17.4 & 1.72 \\
\hline 13 & Hypnotics and sedatives, antianxietics & 1.98 & 138 & 25.9 & 1.15 \\
\hline 14 & Vitamin D receptor activator (VDRA) & 1.72 & 141 & 26.5 & 0.98 \\
\hline 15 & Diuretics & 1.67 & 118 & 22.1 & 1.13 \\
\hline 16 & $\begin{array}{l}\text { Antipyretics, analgesics and } \\
\text { anti-inflammatory agents }\end{array}$ & 1.46 & 83 & 15.6 & 1.41 \\
\hline 17 & Antiallergic agents & 1.16 & 94 & 17.6 & 0.99 \\
\hline 18 & Vitamin preparations (exc. VDRA) & 1.16 & 36 & 6.8 & 2.59 \\
\hline 19 & Chinese medicines & 1.04 & 76 & 14.3 & 1.10 \\
\hline 20 & Cholagogues & 0.78 & 18 & 3.4 & 3.47 \\
\hline 21 & Antihypotensive agents & 0.71 & 91 & 17.1 & 0.63 \\
\hline 22 & Antitussives and expectorants & 0.58 & 35 & 6.6 & 1.32 \\
\hline 23 & Anti-itchings & 0.56 & 34 & 6.4 & 1.33 \\
\hline 24 & Antidysuria agents & 0.56 & 30 & 5.6 & 1.51 \\
\hline 25 & Gastrointestinal prokinetic agents & 0.56 & 25 & 4.7 & 1.79 \\
\hline 26 & Psychotropic agents & 0.54 & 28 & 5.3 & 1.54 \\
\hline 27 & Agents for treatment of gout & 0.50 & 43 & 8.1 & 0.93 \\
\hline 28 & Antiepileptics & 0.42 & 20 & 3.8 & 1.70 \\
\hline 29 & Thyroid preparations & 0.41 & 26 & 4.9 & 1.28 \\
\hline 30 & Adrenal hormone preparations & 0.35 & 17 & 3.2 & 1.65 \\
\hline 31 & Pain relieving agents & 0.32 & 24 & 4.5 & 1.06 \\
\hline 32 & Zinc preparations & 0.27 & 18 & 3.4 & 1.19 \\
\hline 33 & Antimicrobials & 0.12 & 19 & 3.6 & 0.52 \\
\hline 34 & Agents used for common cold & 0.12 & 18 & 3.4 & 0.53 \\
\hline 35 & Others (less than 10 prescribed-patients) & 1.77 & 63 & 11.8 & 2.25 \\
\hline
\end{tabular}




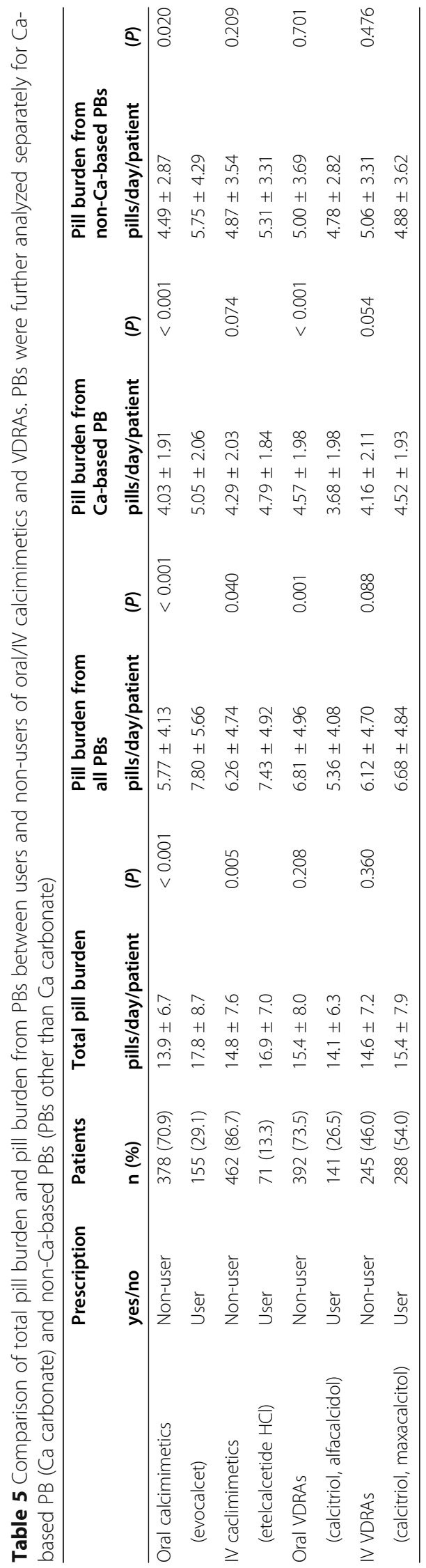


Table 6 Multiple regression analyses accounting for factors that affect total pill burden and pill burden from PBs

\begin{tabular}{|c|c|c|c|c|c|}
\hline & & \multicolumn{2}{|l|}{ Model 1} & \multicolumn{2}{|l|}{ Model 2} \\
\hline & & $\begin{array}{l}\text { Total pill burden } \\
\text { (pills/day/patient) }\end{array}$ & $\begin{array}{l}\text { Pill burden from PBs } \\
\text { (pills/day/patient) }\end{array}$ & $\begin{array}{l}\text { Total pill burden } \\
\text { (pills/day/patient) }\end{array}$ & $\begin{array}{l}\text { Pill burden from PBs } \\
\text { (pills/day/patient) }\end{array}$ \\
\hline Gender (male) & $\begin{array}{l}\beta \\
(P)\end{array}$ & & $\begin{array}{l}0.097 \\
0.040\end{array}$ & & \\
\hline Age (years) & $\begin{array}{l}\beta \\
(P)\end{array}$ & $\begin{array}{l}-0.110 \\
0.011\end{array}$ & $\begin{array}{l}-0.250 \\
<0.001\end{array}$ & $\begin{array}{l}-0.090 \\
0.037\end{array}$ & $\begin{array}{l}-0.255 \\
<0.001\end{array}$ \\
\hline Dialysis vintage (years) & $\begin{array}{l}\beta \\
(P)\end{array}$ & $\begin{array}{l}0.290 \\
<0.001\end{array}$ & $\begin{array}{l}0.175 \\
<0.001\end{array}$ & $\begin{array}{l}0.220 \\
<0.001\end{array}$ & $\begin{array}{l}0.145 \\
0.003\end{array}$ \\
\hline DM (yes) & $\begin{array}{l}\beta \\
(P)\end{array}$ & $\begin{array}{l}0.135 \\
0.003\end{array}$ & & $\begin{array}{l}0.141 \\
0.001\end{array}$ & \\
\hline Serum $P(m g / d L)$ & $\begin{array}{l}\beta \\
(P)\end{array}$ & $\begin{array}{l}0.210 \\
<0.001\end{array}$ & $\begin{array}{l}0.144 \\
0.003\end{array}$ & $\begin{array}{l}0.196 \\
<0.001\end{array}$ & $\begin{array}{l}0.140 \\
0.004\end{array}$ \\
\hline Oral calcimimetics (user) & $\begin{array}{l}\beta \\
(P)\end{array}$ & & & $\begin{array}{l}0.175 \\
<0.001\end{array}$ & $\begin{array}{l}0.106 \\
0.032\end{array}$ \\
\hline IV calcimimetics (user) & ${ }_{(P)}^{\beta}$ & & & $\begin{array}{l}0.094 \\
0.034\end{array}$ & \\
\hline
\end{tabular}

Independent variables in model 1; gender (male), age (years), dialysis vintage (years), DM (yes), serum corrected Ca (mg/dL), serum P (mg/dL), serum i-PTH (pg/ $\mathrm{mL})$, serum Alb ( $\mathrm{g} / \mathrm{dL})$, and $\mathrm{nPCR}$ (g/kg/day). Independent variables in model 2; model 1 + oral calcimimetics (user), IV calcimimetics (user), oral VDRAs (user), and IV VDRAs (user)

burden from "oral calcimimetics" itself was 1.18 pills, resulting in an increase in the total pill burden. Second, because of higher serum $P$ levels in users $(5.53 \pm 1.05$ $\mathrm{mg} / \mathrm{dL}$ vs. $5.25 \pm 1.24 \mathrm{mg} / \mathrm{dL}$ in non-users, $P<0.001$ ), more PBs were prescribed. Third, more Ca carbonate pills were prescribed to compensate for Ca-lowering effects of calcimimetics. Fourth, the patients prescribed calcimimetics may have had more comorbidities besides secondary hyperparathyroidism due to the longer dialysis vintage: $9.9(5.0-16.0)$ years vs. $3.5(1.6-6.8)$ years in non-users, $P<0.001$. On the other hand, the pill burden from all PBs and from Ca-based PB was lower in oral VDRAs users compared with non-users. The pills of $\mathrm{Ca}$ carbonate constituted about half of all PBs. Therefore, it is considered that this result reflects that fewer Ca carbonate pills were prescribed to avoid hypercalcemia in oral VDRA users.

Our study had some limitations. First, this was a single-center study, and as such, it may be difficult to extrapolate our results to other institutions. However, 533 patients were included, which is higher than the number reported from other facilities $[6,8,11,12]$. In addition, since the pill burden from PBs was almost the same as the result of DOPPS [9], the present results may be considered to represent the prescription status in other facilities in Japan. Second, the number of pills depends on the formulation of its preparation used in the facility. For example, a pill containing $500 \mathrm{mg}$ of $\mathrm{Ca}$ carbonate is prescribed in our hospital, but this is counted as two pills in the facility where only the $250 \mathrm{mg}$ formulation is used. Third, it is considered that the number of prescribed pills would be influenced by drug adherence, but it was not considered in this study. In a preliminary study, approximately $60-70 \%$ of patients at our facility showed good drug adherence. Therefore, this study is only based on the number of prescribed pills and not on the number of pills actually taken by patients. Lastly, gender, age, dialysis vintage, DM, serum $\mathrm{Ca}, \mathrm{P}, \mathrm{i}-\mathrm{PTH}$, Alb levels, and nPCR were variables in this study; however, other patient backgrounds were not investigated at all. Further analysis is needed, including comorbidities other than DM and other serum chemistries.

\section{Conclusions}

A high pill burden is more likely to occur in younger patients with longer dialysis vintage, DM, higher serum $\mathrm{P}$ levels, and prescription of calcimimetics. The present study also suggests a renewed focus on the importance of P management because PB was the single largest contributor to the total pill burden that positively and linearly correlated with serum P levels. It is necessary to demonstrate whether a high pill burden will be reduced by more efficient $\mathrm{P}$ management interventions.

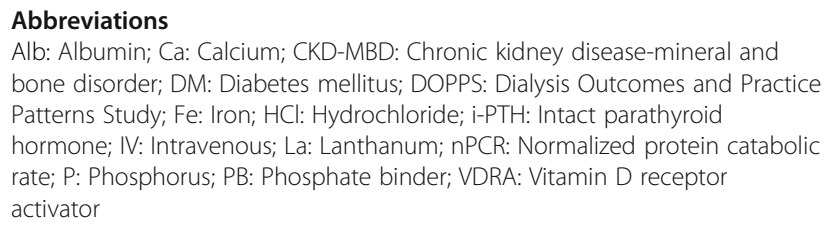

Authors' contributions

NN designed and performed the study, analyzed the data, and wrote the manuscript. $\mathrm{KI}$ and $\mathrm{TT}$ reviewed and revised the manuscript, and T Ogawa is 
responsible for the final version of the manuscript. KI, YA, SM, HK, TA, and TT were responsible for the drug prescription for patients. T Ono contributed to the data of $\mathrm{nPCR}$. KI, TA, and T Ogawa supervised the study. The authors read and approved the final version of this manuscript.

\section{Funding}

None declared.

\section{Availability of data and materials}

The datasets used and analyzed during the current study are available from the corresponding author on reasonable request.

\section{Ethics approval and consent to participate}

The study was conducted in accordance with the guidelines of the Declaration of Helsinki and approved by the Hidaka Hospital Medical Ethics Committee (approval number: Heisei Hidaka Clinic 29). Consent to participate is not applicable.

\section{Consent for publication}

Not applicable.

\section{Competing interests}

NN has received consulting fees from Kyowa Kirin Co., Ltd (KK) and Sanwa Kagaku Kenkyusho Co., Ltd and lecture fees from KK, Nobelpharma Co., Ltd, Torii Pharmaceutical Co., Ltd, Ono Pharmaceutical Co., Ltd (Ono), and Kissei Pharmaceutical Co., Ltd. T Ogawa has received grants (research support) from Takeda Pharmaceutical Co., Ltd, Chugai Pharmaceutical Co., Ltd, Ono, Mitsubishi Tanabe Pharma Co., Ltd, and Daiichi Sankyo Co., Ltd. The other authors declare that they have no competing interests.

\section{Received: 17 September 2020 Accepted: 21 January 2021}

Published online: 04 February 2021

\section{References}

1. Alomar MJ. Factors affecting the development of adverse drug reactions (Review article). Saudi Pharm J. 2014;22:83-94.

2. Rodrigues MC, Oliveira C. Drug-drug interactions and adverse drug reactions in polypharmacy among older adults: an integrative review. Rev Lat Am Enfermagem. 2016;24:e2800

3. Wigneswaran J, St Peter WL, Nissenson AR, et al. Redefining medication management in dialysis: a kidney pharmacy quality pyramid. Kidney Med. 2019;1:307-14

4. Masnoon N, Shakib S, Kalisch-Ellett L, Caughey GE. What is polypharmacy? A systematic review of definitions. BMC Geriatr. 2017;17:230.

5. Manley HJ, Garvin CG, Drayer DK, et al. Medication prescribing patterns in ambulatory haemodialysis patients: comparisons of USRDS to a large notfor-profit dialysis provider. Nephrol Dial Transplant. 2004;19:1842-8.

6. Chiu YW, Teitelbaum I, Misra M, de Leon EM, Adzize T, Mehrotra R. Pill burden, adherence, hyperphosphatemia, and quality of life in maintenance dialysis patients. Clin J Am Soc Nephrol. 2009;4:1089-96.

7. Wang S, Alfieri T, Ramakrishnan K, Braunhofer P, Newsome BA. Serum phosphorus levels and pill burden are inversely associated with adherence in patients on hemodialysis. Nephrol Dial Transplant. 2014;29:2092-9.

8. Parker K, Nikam M, Jayanti A, Mitra S. Medication burden in CKD-5D: impact of dialysis modality and setting. Clin Kidney J. 2014;7:557-61.

9. Fissell RB, Karaboyas A, Bieber BA, et al. Phosphate binder pill burden, patient-reported non-adherence, and mineral bone disorder markers: Findings from the DOPPS. Hemodial Int. 2016:20:38-49.

10. Iwashita $Y$, Ohya M, Kunimoto $S$, et al. A survey of drug burden in patients undergoing maintenance hemodialysis in Japan. Intern Med. 2018;57:293744.

11. Imai N, Osako K, Kaneshiro N, Shibagaki Y. Daily pill burden and pill burden from phosphate binders in Japanese dialysis patients: single center study. Saudi J Kidney Dis Transpl. 2019;30:554-6.

12. Murasawa M, Uehara A, Suzuki T, et al. Association between pill burden and interdialytic weight gain in patients with hemodialysis: a multi-center crosssectional study. Ther Apher Dial. 2020. https://doi.org/10.1111/1744-9987. 13585 Epub ahead of print. PMID: 32945614

13. Ministry of Internal Affairs and Communications. https://www.soumu.go.jp/ main_content/000294493.pdf. Accessed 29 Jan 2021.
14. Akizawa T, Ikejiri K, Kondo $Y$, Endo $Y$, Fukagawa M. Evocalcet: a new oral calcimimetic for dialysis patients with secondary hyperparathyroidism. Ther Apher Dial. 2020;24:248-57.

15. Wada M, Kawata T, Nagano N. Calcimimetics for treating hyperparathyroidism. In: Zaidi M, editor. Encyclopedia of bone biology. 1st ed. New York: Academic Press; 2020. p. 697-710.

16. Mizobuchi M, Ogata H. Clinical uses of 22-oxacalcitriol. Curr Vasc Pharmacol. 2014;12:324-8.

17. Laville SM, Metzger M, Stengel B, et al. Evaluation of the adequacy of drug prescriptions in patients with chronic kidney disease: results from the CKDREIN cohort. Br J Clin Pharmacol. 2018:84:2811-23.

18. Schmidt IM, Hübner S, Nadal J, et al. Patterns of medication use and the burden of polypharmacy in patients with chronic kidney disease: the German Chronic Kidney Disease study. Clin Kidney J. 2019;12:663-72.

19. Fukagawa $M$, Yokoyama $K$, Koiwa $F$, et al. Clinical practice guideline for the management of chronic kidney disease-mineral and bone disorder. Ther Apher Dial. 2013;17:247-88.

20. Lopes AA, Tong L, Thumma J, et al. Phosphate binder use and mortality among hemodialysis patients in the Dialysis Outcomes and Practice Patterns Study (DOPPS): evaluation of possible confounding by nutritional status. Am J Kidney Dis. 2012;60:90-101.

\section{Publisher's Note}

Springer Nature remains neutral with regard to jurisdictional claims in published maps and institutional affiliations.
Ready to submit your research? Choose BMC and benefit from:

- fast, convenient online submission

- thorough peer review by experienced researchers in your field

- rapid publication on acceptance

- support for research data, including large and complex data types

- gold Open Access which fosters wider collaboration and increased citations

- maximum visibility for your research: over $100 \mathrm{M}$ website views per year

At $\mathrm{BMC}$, research is always in progress.

Learn more biomedcentral.com/submissions 